\title{
Chitosan-coated liposomes loaded with butyric acid demonstrate anticancer and anti-inflammatory activity in human hepatoma HepG2 cells
}

\author{
VINCENZO QUAGLIARIELLO ${ }^{1}$, MARIO MASARONE ${ }^{3}$, EMILIA ARMENIA ${ }^{2}$, ALDO GIUDICE ${ }^{4}$, \\ MANLIO BARBARISI $^{5}$, MICHELE CARAGLIA ${ }^{6}$, ALFONSO BARBARISI $^{2}$ and MARCELLO PERSICO $^{3}$
}

\begin{abstract}
${ }^{1}$ Division of Cardiology, Istituto Nazionale Tumori, IRCCS Fondazione G. Pascale, I-80131 Naples; ${ }^{2}$ Department of Thoracic and Cardio-Respiratory Sciences, University of Campania 'Luigi Vanvitelli', I-80138 Naples; ${ }^{3}$ Internal Medicine and Hepatology Division, Department of Medicine, University of Medicine of Salerno, Salerno, I-80123 Naples; ${ }^{4}$ Istituto Nazionale Tumori IRCCS Fondazione Pascale, I-80131 Napoli; Departments of ${ }^{5}$ Medical, Surgical, Neurological, Metabolic and Aging Sciences and ${ }^{6}$ Precision Medicine, University of Campania 'Luigi Vanvitelli', I-80138 Naples, Italy
\end{abstract}

Received April 22, 2018; Accepted October 17, 2018

DOI: $10.3892 /$ or.2018.6932

\begin{abstract}
Butyric acid (BA) has been reported to induce anticancer effects on hepatocellular carcinoma (HCC) cells both in vitro and in vivo. However, its delivery and release in cancer tissues must be optimized. On the basis of these requirements, we prepared liposomes coated with chitosan and uncoated liposomes and both types were loaded with BA through a thin-film hydration method. The liposomes coated or uncoated with chitosan had a mean hydrodynamic size of 83.5 and $110.3 \mathrm{~nm}$, respectively, with a homogeneous size distribution of the particles. For evaluation of the biological effects of the nanoformulations, the hepatoblastoma (HB) HepG2 cell line was utilized. BA-loaded liposomes coated with chitosan showed a considerable higher cytotoxicity than both uncoated liposomes and free $\mathrm{BA}$, with $\mathrm{IC}_{50}$ values, after $72 \mathrm{~h}$ of incubation, of 7.5, 2.5 and $1.6 \mathrm{mM}$, respectively. Treatment of HepG2 cells for $5 \mathrm{~h}$ with the BA-loaded liposomes coated with chitosan at $5 \mathrm{mM}$ lowered the extent of the increase in IL-8, IL- 6 , TNF- $\alpha$ and TGF- $\beta$ expression of approximately $64,58,85$ and $73.8 \%$, respectively, when compared to the untreated cells. The BA-loaded liposomes coated with chitosan had marked capacity to be internalized in human HB cells showing an increased cytotoxic activity when compared with free BA and important anti-inflam-
\end{abstract}

Correspondence to: Dr Vincenzo Quagliariello, Division of Cardiology, Istituto Nazionale Tumori, IRCCS Fondazione G. Pascale, I-80131 Naples, Italy

E-mail: quagliariello.enzo@gmail.com

Professor Michele Caraglia, Department of Precision Medicine, University of Campania 'Luigi Vanvitelli', I-80138 Naples, Italy

E-mail: michele.caraglia@unicampania.it

Key words: liposome, butyric acid, liver cells, inflammation, cytokines matory effects by inhibiting production of cytokines with a central role in liver cell survival.

\section{Introduction}

The liver has a key role in the metabolism and detoxification of drugs. This role induces the exposure of the liver to metabolites and toxins that, in turn, can cause chronic inflammation (1) and in some cases the development and pathogenesis of acute and chronic hepatic diseases (2-4). Chronic inflammation of the liver causes cellular damage and the deposit of a high amount of lipids in the hepatocytes which is associated with a higher risk of steatohepatitis, fibrosis and cancer (5-9). In detail, liver tissue consists of several cell components involved in inflammatory processes. These cell components include leukocytes and Kupffer cells, that can be stimulated by toxins or other inflammatory reactions to produce cytokines such as transforming growth factor (TGF)- $\beta$, tumor necrosis factor (TNF)- $\alpha$ and interleukin (IL)-6 (10). Among these, TNF- $\alpha$ activates several intracellular pathways regulating inflammation, cell death and proliferation $(11,12)$. TNF- $\alpha$ is mainly produced in response to lipopolysaccharides (LPS) and other bacterial products. During hepatocyte injury, Kupffer cells are able to produce TNF- $\alpha$ which increases the secretion of IL- 6 in an autocrine manner with subsequent induction of hepatocyte proliferation. IL-6 is crucial for hepatocyte homeostasis and mitogenic activity; in fact, it is involved in liver regeneration but extended activation of the IL-6/IL-6-R signaling pathway is crucial in the initiation and progression of hepatocellular carcinoma (HCC) $(13,14)$. In patients affected by HCC, a high amount of macrophages infiltrating in the tumor is correlated with the negative prognosis of the disease. This finding can be due to IL-6 hypersecretion that, in turn, increases the generation of HCC progenitor cells (HcPCs). Moreover, TGF- $\beta$ is a growth factor with pro-fibrogenic and immunosuppressive activity $(15,16)$. Therefore, its expression induces hepatocyte death and metabolic modulation of cells involved in the wound-healing response such as hepatic stellate cells and liver 
fibroblasts $(17,18)$. Overexpression of TGF- $\beta$ is involved in several liver diseases (19) and could be directly involved in the tumorigenic process (20).

During the last few years, great emphasis has been given to the 'gut-liver axis', and on the role of intestinal bacterial flora in inducing positive or negative effects on liver health protecting tissue from inflammatory injuries (21). For example, saccharolytic fermentation (carried out mainly by Lactobacillus spp) of unabsorbed and indigestible carbohydrates of soluble dietary fibres, is an essential mechanism leading to the production of short-chain fatty acids (SCFAs) (i.e. acetate, propionate and butyrate) that display a well-known anti-inflammatory action in liver tissues (22-24). Among the SCFAs, intestinal epithelial cells derive the most useful energy for processes such as proliferation and differentiation, secretion of mucus, decrease in inflammation in different organs, from butyric acid (BA). Specifically, BA decreases the production of cytokines such as IL-6, IL-8, TNF- $\alpha$ and TGF- $\beta$, that have a central function in liver inflammation and are involved in triggering fibrosis as well as cancer $(25,26)$. However, oral administration of BA is clinically not easy due to both its unpleasant taste and inefficient intestinal absorption $(27,28)$. Nevertheless, in the last few years some randomized controlled trials have demonstrated the beneficial effects of BA after oral administration even though an important limitation in these clinical trials was its low bio-availability due to the interference of gut microbiota that can change its concentration and absorption (29). The recent use of nanotechnology in medicine has brought important advances in the delivery of drugs in inflamed and cancer tissues. In light of this, liposomes are lipidic nanocarriers able to protect a drug from the external environment, enzymatic attack and immune recognition with consequently increased bioavailability, controlled drug delivery, biodistribution in targets such as cancer tissues and reduced toxicity (30-32). Liposomes and other nanocarriers are directly involved in altering the biodistribution of certain anticancer agents that cannot be efficiently delivered, in their free formulation, in cancer tissues or cannot be appropriately adsorbed by the gut (33). Liposomes loaded with bioactive molecules, such as polyphenol or SCFAs, and orally administered can represent important tools with which to enhance bio-drug plasma concentration and specific delivery to the liver $(34,35)$. For the oral administration of liposomes, surface liposome coating with natural polymers could be an efficient strategy to increase gut absorption and, among these, chitosan is one of the most promising. Chitosan is a natural polysaccharide derived from chitin and due to its properties, such as hydrophilicity, bioadhesivity, biocompatibility, biodegradability and low toxicity can be considered as a novel drug delivery system that improves the oral bioavailability of drugs by prolonging the residence time at the site of intestinal absorption (36). Moreover, chitosan induces a redistribution of cytoskeletal F-actin and tight junction protein $\mathrm{ZO}-1$ via interaction between its positive charges and the enterocyte surface negative charges, which results in increased paracellular permeability for hydrophilic macromolecules. In the present study, we investigated the in vitro anticancer activity and anti-inflammatory properties of chitosan-coated and -uncoated liposomes loaded with BA in hepatoblastoma (HB) HepG2 cells (37).

\section{Materials and methods}

Materials. Butyric acid, cholesterol, sodium phosphatidylcholines, fluoresceineamine (FA), Spectra/Por Biotech cellulose ester membrane (cut-off $5 \mathrm{kDa}$ ) and ethanol were purchased from Sigma-Aldrich/Merck KGaA (Milan, Italy). To carry out synthesis and characterization, we used purified and distillated water by reverse osmosis (Milli-Q Plus; Thermo Fisher Scientific, Milan, Italy).

\section{Methods.}

Synthesis and chemical characterization of liposomes and fluorescent liposomes. Thin-film hydration tecnique was used to prepare liposomes either loaded or not with BA and chitosan-coated or uncoated, as previously described (38) but with some modifications (36). Specifically, as an example for the synthesis of uncoated liposomes loaded with BA, we used chloroform to dissolve sodium phosphatidylcholines (SPC)/ cholesterol/butyric acid (20/5/4, w/w) and rotary evaporation at $37^{\circ} \mathrm{C}$ to dry and form a thin film. The organic solvent was completely removed by drying under vacuum. To hydrate the thin film we used $20 \mathrm{ml}$ of $50 \mathrm{mM}$ citric acid and this solution was shaken and mixed. Finally, the $\mathrm{pH}$ of the suspension was adjusted to 6.8 with $50 \mathrm{mM} \mathrm{Na} \mathrm{CO}_{3}$ and, in order to obtain small and homogeneous liposomes, the obtained nanocarriers were sonicated for $10 \mathrm{~min}(1 \mathrm{mHz})$ by using a sonicator (Sonics VCX 500 Vibra Cell $^{\mathrm{TM}}$; Sonics \& Materials, Inc., Newton, CT, USA). An aliquot of liposomes loaded with BA was added with the same volume of chitosan $(0.1 \%)$ in PBS (phosphatebuffered saline; $\mathrm{pH}$ 6.8) and then incubated at $4^{\circ} \mathrm{C}$ for $1 \mathrm{~h}$ to prepare the chitosan-coated liposomes loaded with BA.

For the biological studies of cellular internalization and imaging by confocal laser scanning microscopy (CLSM) fluorescently, chitosan-coated and -uncoated liposomes were prepared with a solution of $0.1 \mathrm{mg} / \mathrm{ml}$ of fluoresceineamine (FA) in PBS to the lipid solution before preparing liposomes as described before. The particle sizes and zeta $(\zeta)$ potentials of the final products were measured with a Zetasizer ZS nano series ZEN 3600 (Malvern Instruments Ltd., Malvern, UK) and 50 runs were carried out for each measurement for $\zeta$ potential analysis, whereas the default refractive index ratio (1.52) and 5 runs for each measurement (1 run lasting $100 \mathrm{sec}$ ) were used in the calculations of the particle size distribution.

Cell viability. To evaluate the cytotoxicity of all substances on human hepatoblastoma (HB) HepG2 cells (HB-8065 ${ }^{\mathrm{TM}}$; ATCC $^{\circledR}$, American Type Culture Collection, Manassas, VA, USA), through their mitochondrial dehydrogenase activity, a modified MTT test [3-(4,5-dimethyldiazol-2-yl)-2,5diphenyltetrazolium bromide] was carried out according to the manufacturer's instructions (Dojindo Molecular Technologies Inc., Rockville, MD, USA). Specifically, the culture medium used to grow the HepG2 cell line (HB-8065 ATCC) was Dulbecco's modified Eagle's medium (DMEM; Sigma Aldrich S.L.R., Milan, Italy) supplemented with $10 \%$ FBS and 1\% Pen-Strep and cells was seeded in 96-well plates at a density of 10,000 cells per well at $37^{\circ} \mathrm{C}$ in a humidified $5 \% \mathrm{CO}_{2}$ atmosphere. After $24 \mathrm{~h}$ of growth, the following formulations were added to the cells in full medium: empty liposomes (Lip), empty chitosan-coated liposomes 
(Chit-Lip), uncoated liposomes loaded with BA (Lip-BA), chitosan-coated liposomes loaded with BA (Chit-Lip-BA), free BA (BA); for both loaded nanocarriers and free BA the fatty acid was tested always at the corresponding concentrations ranging from 0.05 to $10 \mathrm{mM}$. Cells were then incubated from 24 to $72 \mathrm{~h}$ under standard conditions and subsequently the cells were washed three times with PBS at $\mathrm{pH} 7.4$ and incubated with $100 \mu 1$ with a MTT solution $(0.5 \mathrm{mg} / \mathrm{ml}$ in cell culture medium) for $4 \mathrm{~h}$ at $37^{\circ} \mathrm{C}$. Tecan Infinite M200 plate-reader (Tecan Group, Ltd., Mannedorf, Switzerland) with I-control software (Tecan Infinite i-control 1.8.50.0) was used to acquire the absorbance at $450 \mathrm{~nm}$. The relative cell viability (\%) was calculated by the formula $[\mathrm{A}]_{\text {test }} /$ $[\mathrm{A}]_{\text {control }} \times 100$, where ' $[\mathrm{A}]_{\text {test }}$ ' is the absorbance of the test sample, and ' $[\mathrm{A}]_{\text {control' }}$ ' is the absorbance of the control cells incubated solely with culture medium. After this evaluation was carried out, the Micro BCA protein assay kit (Pierce) was utilized to quantify total protein content. This method provides washing of the cells with ice-cold PBS, and the incubation of these for $15 \mathrm{~min}$ in $150 \mu \mathrm{l}$ of lysis buffer $(0.5 \%$ $\mathrm{v} / \mathrm{v}$ Triton X-100 in PBS), and $150 \mu 1$ of Micro BCA protein assay kit reagent (prepared following the instructions of the manufacturer) and finally the absorbance was measured at $562 \mathrm{~nm}$. The cytotoxicity measurements were then normalized by the amount of total protein content in each well.

Cellular uptake studies. Imaging by confocal laser scanning microscope. The culture medium used to grow the HepG2 cells (HB-8065 ATCC) was DMEM supplemented with 10\% FBS and $1 \%$ Pen-Strep and cells were seeded in 24-well plates at a density of $5 \times 10^{3}$ cells/well at $37^{\circ} \mathrm{C}$ in a humidified $5 \% \mathrm{CO}_{2}$ atmosphere for $24 \mathrm{~h}$. For the imaging studies, we followed the same procedure described in the literature $(39,40)$ where the medium was replaced with $0.3 \mathrm{mg} / \mathrm{ml}$ of Chit-Lip-FA solution in culture medium and incubated for 0.5, 4, 8 and $24 \mathrm{~h}$; after incubation time with fluorescent liposomes, the cells were washed three times with PBS and fixed with $2.5 \%$ glutaraldehyde in PBS for $20 \mathrm{~min}$. Concanavalin A tetramethylrhodamine conjugate (Invitrogen, Life Technology; Thermo Fisher Scientific, Inc., Waltham, MA, USA) was used to stain the membrane at a final concentration of $100 \mu \mathrm{g} / \mathrm{ml}$. After washing in PBS, human cells were blocked with $1 \%$ BSA in PBS for 20 min and washed three times with PBS. For data acquisition, we used a confocal microscope (C1 Nikon; Nikon Cor., Tokyo, Japan) with EZ-C1 software (Nikon Corp.) and 60x or 100x oil immersion objective, imaging of the fluorescent liposomes was evaluated by excitation/emission at 492/518 nm, and the cell membrane with excitation/emission at 555/580 $\mathrm{nm}$.

Quantification of uptake. The culture medium used to grow HepG2 cells (ATCC HB-8065) was supplemented with DMEM with $10 \%$ FBS and $1 \%$ Pen-Strep and cells were seeded in 24-well plates at a density of $5 \times 10^{3}$ per well at $37^{\circ} \mathrm{C}$ in a humidified $5 \% \mathrm{CO}_{2}$ atmosphere for $24 \mathrm{~h}$. For uptake quantification, we followed the same protocol used in our previous work (32). Substantially, each well with the proper cell concentration was washed and $0.1 \mathrm{ml}$ of $1 \mathrm{mg} / \mathrm{ml}$ solution of either fluorescent uncoated (Lip-FA) or chitosan-coated (Chit-Lip-FA) liposomes was added to the culture medium and cells were incubated for a time ranging from 0.5 to $24 \mathrm{~h}$. After this time, the supernatant was removed and cells were washed three times with $10 \mathrm{mM}$ PBS and, then, the lysate with $0.1 \mathrm{ml}$ of $0.5 \%$ Triton X-100 in $0.2 \mathrm{~N} \mathrm{NaOH}$. The fluorescence of the cell lysate $\left(\lambda_{\text {exc }}=485 \mathrm{~nm}, \lambda_{\mathrm{em}}=535 \mathrm{~nm}\right)$ allowed the evaluation and quantification of the membrane-bound and internalized fluorescent liposomes, using a calibration curve ranged from 0.001 up to $0.6 \mathrm{mg} / \mathrm{ml}$ of fluorescent liposomes dispersed in a cell lysate solution $\left(10^{6}\right.$ untreated cells dissolved in $1 \mathrm{ml}$ of the Triton X-100/0.2 N NaOH solution). For both calibration curve and Lip-FA/Chit-Lip-FA cellular uptake determination, the fluorescence was measured at the proper wavelengths by using a spectrofluorometer (xMark Microplate spectrofluorometer; Bio-Rad Laboratories, Milan, Italy).

Mechanistic studies. In order to understand the mechanisms of liposome internalization in HepG2 cells, we studied the effects of specific pharmacological treatments, such as bafilomycin A1 [selective reversible inhibitor of vacuolar $\mathrm{H}^{+}$-ATPases (V-ATPases) which inhibits autophagy by preventing vacuolar acidification necessary for autophagosome maturation] $(41,42)$, filipin (inhibitor of caveolae-mediated endocytosis), nocodazol (rapidly reversible inhibitor of microtubule polymerization), cytochalasin D (a well-known selective inhibitor of actin polymerization), hypertonic sucrose and potassium-free buffer (which inhibit the clathrin-mediated uptake with lower or higher selectivity, respectively) and sodium azide (a metabolic inhibitor of cell respiration,

Cell uptake experiments were performed at $4 \mathrm{~h}$ of incubation with fluorescent uncoated (Lip-FA) and chitosan-coated (Chit-Lip-FA) liposomes in the presence of these inhibitors, specifically: $0.45 \mathrm{M}$ sucrose, $0.1 \mathrm{mg} / \mathrm{ml}$ of cytochalasin $\mathrm{D}$, $1 \mathrm{mg} / \mathrm{ml}$ of nocodazole, $0.1 \mathrm{mg} / \mathrm{ml}$ of filipin and $2 \times 10^{-7} \mathrm{M}$ of bafilomycin A1. To quantify the energy dependence of the process, we performed other experiments in which cancer cells were incubated with $10^{-2} \mathrm{M}$ of sodium azide for $30 \mathrm{~min}$ prior to liposome uptake. HepG2 cells were pre-incubated at $4^{\circ} \mathrm{C}$ for $30 \mathrm{~min}$ with inhibitors and then at $37^{\circ} \mathrm{C}$ for $4 \mathrm{~h}$ without them, as previously reported (43). In order to study the effect of intracellular potassium depletion, HepG2 cells were rinsed twice and incubated with a potassium-free buffer solution with the following substances: $0.14 \mathrm{M} \mathrm{NaCl}, 0.02 \mathrm{M}$ of MES buffer, $10^{-3} \mathrm{M}$ of $\mathrm{CaCl}_{2}$ and $1 \mathrm{mg} / \mathrm{ml}$ of glucose $\mathrm{pH} 7.4$ for $30 \mathrm{~min}$ before uptake experiments were performed in the same medium, as previously reported (44).

Analysis of cytokine expression. With the ELISA test, it was possible to assess the expression of IL-6, IL-8, TGF- $\beta$ and TNF- $\alpha$ in human HB cells, following the same procedure previously published by our group (45). Briefly, HepG2 cells $\left(1.2 \times 10^{5}\right.$ cells/well $)$ were seeded in 12 -well plates in DMEM supplemented with $10 \% \mathrm{FBS}$ and $1 \%$ Pen-Strep at $37^{\circ} \mathrm{C}$ in a humidified $5 \% \mathrm{CO}_{2}$ atmosphere. Thereafter, the cells were incubated for $24 \mathrm{~h}$ in serum-free medium for $2.5 \mathrm{~h}$. Subsequently, the cells were incubated with or without $0.1 \mathrm{ml}$ of unformulated butyric acid or chitosan-coated or uncoated liposomes both loaded with BA (in all cases, fatty acid was tested at $2.5,5$ and $10 \mathrm{mM}$ ) for $5 \mathrm{~h}$ before exposure to LPS $(40 \mathrm{ng} / \mathrm{ml})$ for $12 \mathrm{~h}$. LPS was used to stimulate inflammation. Thereafter, using a VEGF ELISA kit (Sigma Aldrich; Merck KGaA, Milan, Italy) according to the manufacturer's instructions, the quantification 
Table I. Physical-chemical characteristics of the liposomes used: hydrodynamic size, polydispersity index (PDI) and $\zeta$ potential.

\begin{tabular}{lrrr}
\hline Liposomes & $\begin{array}{c}\text { Hydrodynamic } \\
\text { size (SD) }\end{array}$ & PDI (SD) & $\zeta$ potential (SD) \\
\hline Empty liposomes (Lip) & $84.5 \mathrm{~nm}(3.6)$ & $0.26(0.03)$ & $-10.2 \mathrm{mV}(1.2)$ \\
Empty chitosan-coated liposomes (Chit-Lip) & $126.3 \mathrm{~nm}(6.4)$ & $0.18(0.01)$ & $12.2 \mathrm{mV}(1.1)$ \\
Uncoated liposomes loaded with BA (Lip-BA) & $92.1 \mathrm{~nm}(4.1)$ & $0.18(0.05)$ & $-9.3 \mathrm{mV}(1.5)$ \\
Chitosan-coated liposomes loaded with BA (Chit-Lip-BA) & $132.2 \mathrm{~nm}(2.3)$ & $0.22(0.03)$ & $15.3 \mathrm{mV}(2.1)$ \\
Fluorescent uncoated liposomes (Lip-FA) & $88.6 \mathrm{~nm}(4.3)$ & $0.24(0.02)$ & $-12.3 \mathrm{mV}(2.2)$ \\
Fluorescent chitosan-coated liposomes (Chit-Lip-FA) & $119.5 \mathrm{~nm}(3.3)$ & $0.19(0.04)$ & $13.5 \mathrm{mV}(1.6)$ \\
\hline
\end{tabular}

of IL-6 and IL-8 was performed. This assay can detect cytokines in a $10-32.000 \mathrm{pg} / \mathrm{ml}$ range with a sensitivity less than $10(\mathrm{pg} / \mathrm{ml})$.

Statistical analysis. The analysis of variance (ANOVA) and Tukey's multiple comparison test in SigmaPlot Software (Systat Software, Inc., San Jose, CA, USA) was used to analyze the statistical difference between experimental groups. The lowest acceptable significant threshold, for statistical analysis of all data, was $\mathrm{P}<0.05$.

\section{Results}

Synthesis and chemical characterization of the liposomes and fluorescent liposomes. As reported in Table I, the obtained liposomes showed a specific distribution size linked to the presence or absence of the coating on the surface. In fact, uncoated liposomes either empty or loaded with drug or fluorophore had a mean hydrodynamic size of $\sim 88.5 \mathrm{~nm}(88.6 \pm 4.3,92.1 \pm 4.1$, $84.5 \pm 3.6 \mathrm{~nm}$, respectively) with a polydispersity index (PDI) always $<0.3$ indicating a good and homogeneous dispersion of the liposome sizes. On the other hand, the coating of the liposomes with chitosan, as expected, induced an increase in the hydrodynamic size with a mean value of $126 \mathrm{~nm}$ (Table I) and with an acceptable PDI. Regarding $\zeta$ potential, as clearly shown in Table I, coating of the nanocarriers caused the formation of a net positive surface charge of the liposomes indicating in an indirect manner the presence of chitosan on their surface.

Cell viability. As shown in Fig. 1, empty liposomes showed a very slight toxicity against HepG2 cells at all the times and the same concentrations used. Specifically, at a very high concentration of uncoated and coated liposomes, corresponding to $5 \mathrm{mg} / \mathrm{ml}$, after $72 \mathrm{~h}$ of incubation only approximately $15-20 \%$ of the cells were not viable ( $\mathrm{P}<0.05$, compared to the control). This biological behavior is already well known as these lipidic nanocarriers are highly biocompatible and easily metabolized by cells (46). Interestingly, the chitosan coating did not increase cell cytotoxicity against the HB cells, compared to the uncoated ones, in all assessed concentrations indicating a good biocompatibility of the polymer. As reported in the literature (47), free BA showed a marked antitumor effect against human cells without reaching an $\mathrm{IC}_{50}$ (concentration inhibiting the $50 \%$ of cells) value after $24 \mathrm{~h}$ of incubation at all assessed concentrations; only after 48 and $72 \mathrm{~h}$ of incubation the $\mathrm{IC}_{50}$ value was obtained in cells treated with free BA (10 and $4.5 \mathrm{mM}$, respectively) indicating a time-dependent cytotoxicity of the fatty acid against HepG2 cells. On the other hand, formulations of BA encapsulated in both coated and uncoated liposomes induced a significantly improved antiproliferative activity in the HepG2 cells. In detail, uncoated liposomes loaded with BA (Lip-BA) induced an approximately $50 \%$ of cell growth inhibition at $10,5.5$ and $2.7 \mathrm{mM}$ after 24,48 and $72 \mathrm{~h}$ of incubation, respectively, indicating an increase in anticancer activity of about 45 and $40 \%$ after 48 and $72 \mathrm{~h}$ of incubation, respectively, when compared to free BA (Fig. 1). The best results were obtained with the chitosan-coated liposomes (Chit-Lip-BA) that caused an approximately $50 \%$ cell growth inhibition at 7.5, 2.5 and $1.6 \mathrm{mM}$ after 24,48 and $72 \mathrm{~h}$ of incubation, respectively, with a 25,55 and $41 \%(\mathrm{P}<0.05)$ increased cytotoxic activity when compared to the uncoated liposomes, respectively. Comparing unformulated BA with chitosan uncoated and coated liposomes loaded with BA (Fig. 2), it was obvious that, at 48 (Fig. 2B) and 72 h (Fig. 2C) of incubation, there was a statistically significant difference between Lip-BA and Chit-Lip-BA. These differences, in the same cases, were not significant at $24 \mathrm{~h}$ of incubation (at 1.5 and $2.5 \mathrm{mM}$ of BA) (Fig. 2A). However, these findings suggest that BA cytotoxicity against human HB cells was greatly improved by its encapsulation in liposomes coated with chitosan with an $\mathrm{IC}_{50}$ value at 48 and $72 \mathrm{~h}$ of incubation that was decreased at approximately 75 and $65.5 \%(\mathrm{P}<0.01$ for both) when compared to free BA.

\section{Cellular uptake studies}

Imaging by confocal laser scanning microscope. The images obtained with confocal laser scanning microscope (Fig. 3) showed a time-dependent uptake of fluorescent chitosan-coated liposomes with a perimembrane localization after 0.5 and $4 \mathrm{~h}$ and a perinuclear localization after $24 \mathrm{~h}$ (Fig. 3D). Chitosancoated liposomes appeared to be located especially on the cell membrane and in the juxtamembrane region (Fig. 3A and B) at a short time of incubation (0.5 and $4 \mathrm{~h})$. Notably, the images showed the overall spheric shape of the fluorescent nanocarrier with a characteristic point-like dispersion in the intracellular microenvironment.

Uptake quantification. As shown in Fig. 4A, the uptake of fluorescent-coated and-uncoated liposomes was time-dependent in the HepG2 cells with a statistically significant difference between the two different nanocarriers. Importantly, just after 

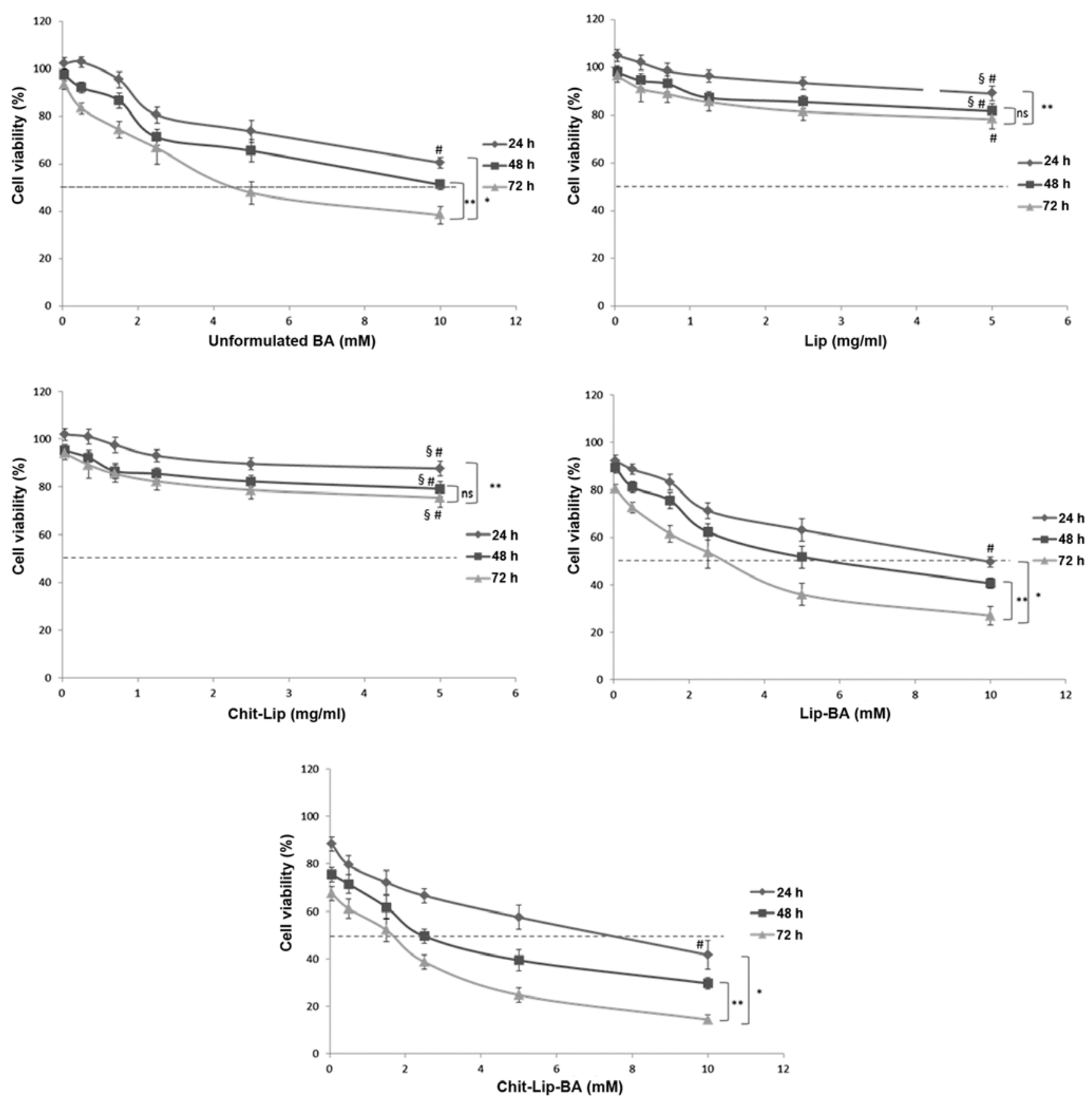

Figure 1. HepG2 cell viability ( \pm SEM) as assessed through modified MTT assay as a function of time (from 24 to $72 \mathrm{~h}$ of incubation time) and concentration of unformulated BA (BA), empty liposomes (Lip), empty chitosan-coated liposomes (Chit-Lip), uncoated liposomes loaded with BA (Lip-BA), chitosan-coated liposomes loaded with BA (Chit-Lip-BA) at BA concentrations ranging from 0.05 to $10 \mathrm{mM}$. ${ }^{*} \mathrm{P}<0.001,{ }^{* * *} \mathrm{P}<0.05$, ns: not significant; ${ }^{*} \mathrm{P}<0.05$ comparing control cells and $10 \mathrm{mM}$ of unformulated BA or Lip-BA or Chit-Lip-BA or $10 \mathrm{mg} / \mathrm{ml}$ of Lip or Chit-Lip. ${ }^{\S} \mathrm{P}<0.05$ comparing Lip and Chit-Lip $0 \mathrm{mg} / \mathrm{ml}$ and $5 \mathrm{mg} / \mathrm{ml}$.

$2 \mathrm{~h}$ of incubation, approximately $25.5 \pm 3.3$ and $47.5 \pm 6 \%$ of the uncoated and coated liposomes, respectively, were internalized in the HepG2 cells while the maximal internalization was observed at $24 \mathrm{~h}$ of incubation. In fact, $65.5 \pm 5$ and $89.5 \pm 2.6 \%$ of the uncoated and coated nanocarriers were found to be incorporated in the cells (Fig. 4A) corresponding to a theoretical overall molar concentration of $\mathrm{BA}$ of 1.31 and $1.79 \mathrm{mM}$, respectively.

Mechanistic studies. As it was established that liposomes can be internalized in human HepG2 cells in a time-dependent manner, by the use of a small library of inhibitors of general active transport processes it can be possible to analyze cell uptake, endosomal acidification, caveolae-mediated endocytosis, membrane ruffling and vescicular transport on microtubuli or actin fibers. These inhibitors had differential effects in HepG2 cells on the internalization of fluorescentcoated and -uncoated liposomes. As shown in Fig. 4B, both nanocarriers had the same internalization mechanism in HepG2 cells. In detail, the inhibition of the endocytosis of chitosan-coated liposomes by sodium azide (62\% of inhibition) and by cytochalasin $\mathrm{D}$ ( $42 \%$ of inhibition) and the absence of any significant effect induced by nocodazole suggested an energy-dependent mechanism of Chit-Lip-FA internalization 

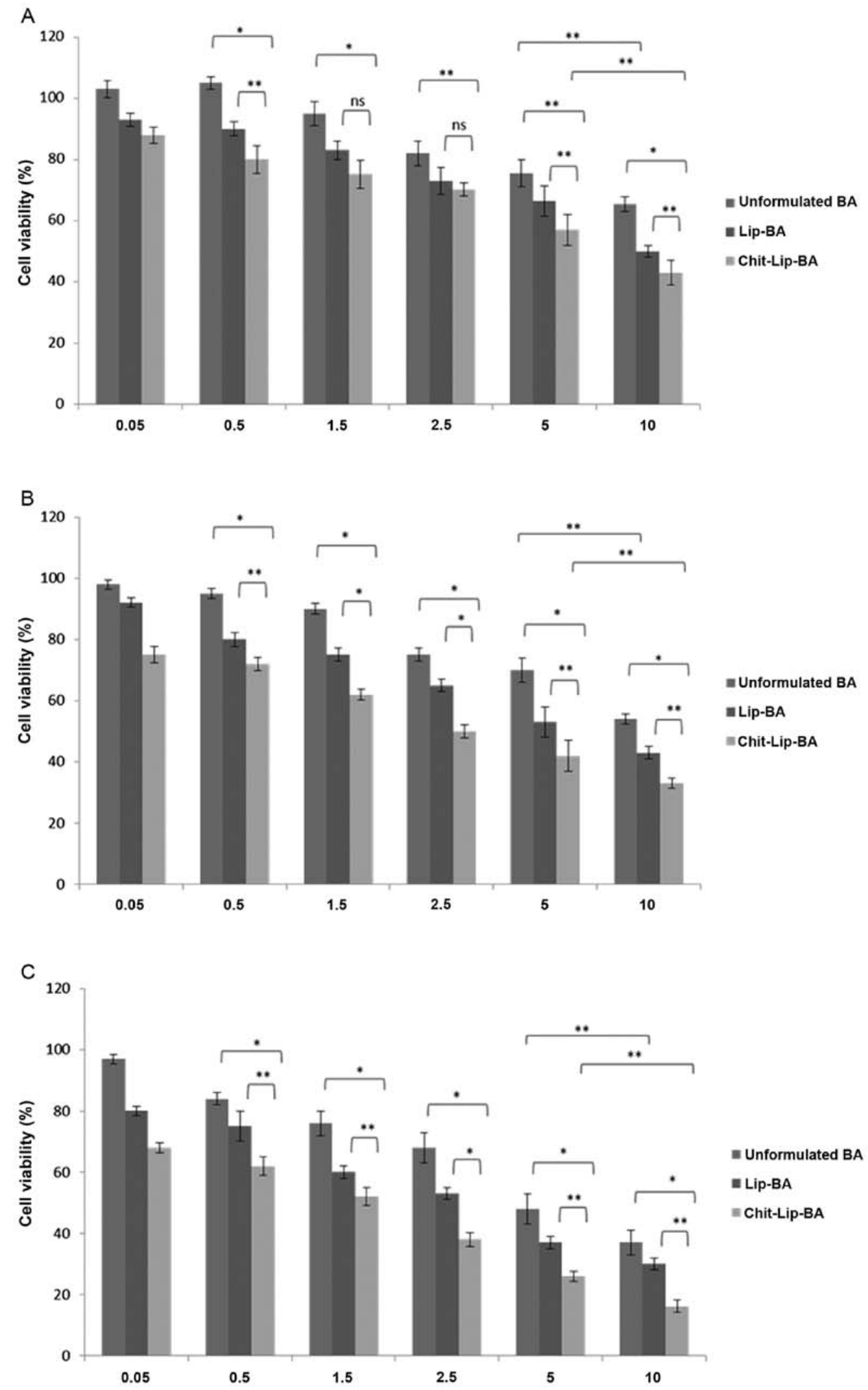

Figure 2. HepG2 cell viability ( \pm SEM) as assessed through modified MTT assay as a function of time [(A) 24 , (B) 48 and (C) $72 \mathrm{~h}]$ and concentration of unformulated BA (BA), uncoated liposomes loaded with BA (Lip-BA) and chitosan-coated liposomes loaded with BA (Chit-Lip-BA) at BA concentration ranging from 0.05 to $10 \mathrm{mM}$. ${ }^{*} \mathrm{P}<0.001,{ }^{* * *} \mathrm{P}<0.05$; ns: not significant.

with the involvement of stress fibers, but not of microtubules; filipin did not inhibit their internalization excluding also a caveolae-mediated endocytic mechanism. On the other hand, bafilomycin A1 caused an approximately $38 \%$ reduction in endocytosis when compared to the control. Clathrin-selective potassium-free buffer ( $42 \%$ of inhibition) exhibited the same 

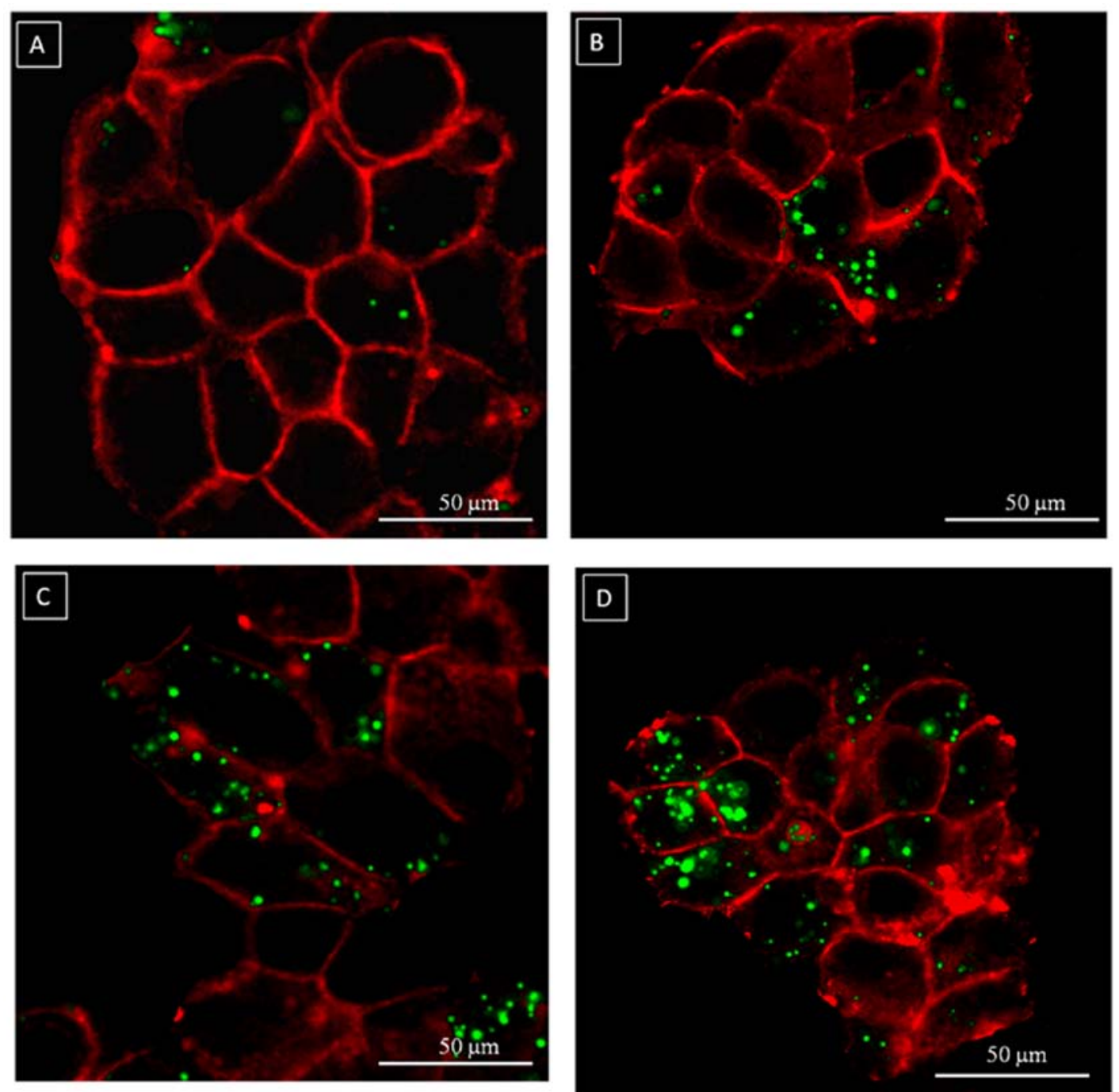

Figure 3. Cellular images by confocal laser scanning microscope of HepG2 cells (5,000 cells/well) after 0.5 (A), 4 (B), 8 (C) and 24 h (D) of incubation with fluorescent chitosan-coated liposomes at $1 \mathrm{mg} / \mathrm{ml}$. Green signal, fluorescent nanocarrier; Red signal, corresponding to cellular membrane labeled with concanavalin A tetramethylrhodamine conjugate. Scale bar, $50 \mu \mathrm{m}$.

inhibitory action as the well-known hypertonic sucrose, that inhibits also macropinocytic and caveolar uptake. These findings demonstrate that a clathrin-dependent endocytosis could be the preferential internalization mechanism in human $\mathrm{HB}$ cells (Fig. 4B).

Evaluation of cytokine expression. Regarding the antiinflammatory properties of free or liposome-encapsulated BA, we observed that pre-treatment with all the assessed substances at the corresponding concentrations of 2.5, 5 and $10 \mathrm{mM}$ consistently induced a significant decrease in IL-8, IL-6, TGF- $\beta$ and TNF- $\alpha$ expression (Fig. 5) when compared to the untreated cells. However, some interesting differences could be recorded. In detail, unformulated BA administration at a concentration of $2.5 \mathrm{mM}$ reduced the increase in the cell amounts of IL-8, IL- 6 , TGF- $\beta$ and TNF- $\alpha$ of approximately $11.8,10.4,20.4$ and $16.7 \%$, respectively, when compared to the LPS-treated HepG2 cells $(\mathrm{P}<0.001)$ (Fig. 5). The antiinflammatory effects were concentration-dependent since following the doubling of the BA concentration, the increase in the cell amounts of IL-8, IL- 6 , TGF- $\beta$ and TNF- $\alpha$ were reduced by approximately 30.6, 20.0, 37.8 and 34.8\%, respectively, compared to the untreated and LPS-treated HB cells $(\mathrm{P}<0.001)$ (Fig. 5). Interestingly, uncoated liposomes loaded with BA consistently induced a higher and statistically significant anti-inflammatory effects than free BA at all assessed concentrations; in fact, they reduced IL- 8 , IL- 6 , TGF- $\beta$ and TNF- $\alpha$ production by $30.0,18.0,53.0$ and $32.4 \%$ at $2.5 \mathrm{mM}$ and $42.0,33.0,68.0$ and $52.0 \%$ at $5 \mathrm{mM}$ of BA concentration, respectively (all values compared to untreated cells, $\mathrm{P}<0.001$ ). On the other hand, chitosan-coated liposomes loaded with BA caused higher anti-inflammatory effects when compared to both free BA and uncoated liposomes loaded with BA at all the assessed concentrations. In detail, they decreased IL-8, IL-6, TGF- $\beta$ and TNF- $\alpha$ production of 46.0, 37.0, 70.0 and $45.6 \%$ at $2.5 \mathrm{mM}$ and $64.0,58.0,85.0$ and $73.8 \%$ at $5 \mathrm{mM}$ BA concentration, respectively (all values compared to untreated cells, $\mathrm{P}<0.001)$. Comparing the two different liposomal formulations, at $5 \mathrm{mM}$ BA concentration, chitosan-coated liposomes encapsulating BA reduced IL-8, IL-6, TGF- $\beta$ and TNF- $\alpha$ production by $22.0,25.0,17.0$ and $22.0 \%$, respectively, more than the uncoated liposomes encapsulating BA. These 


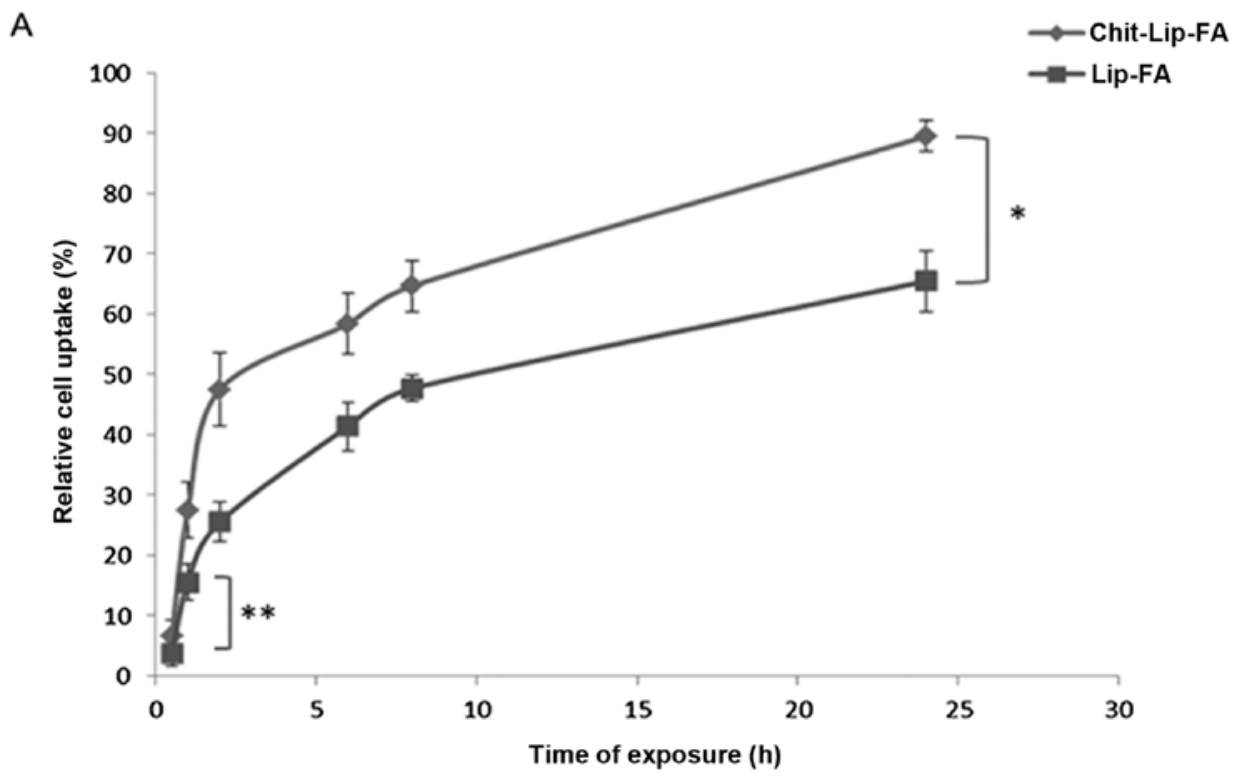

B

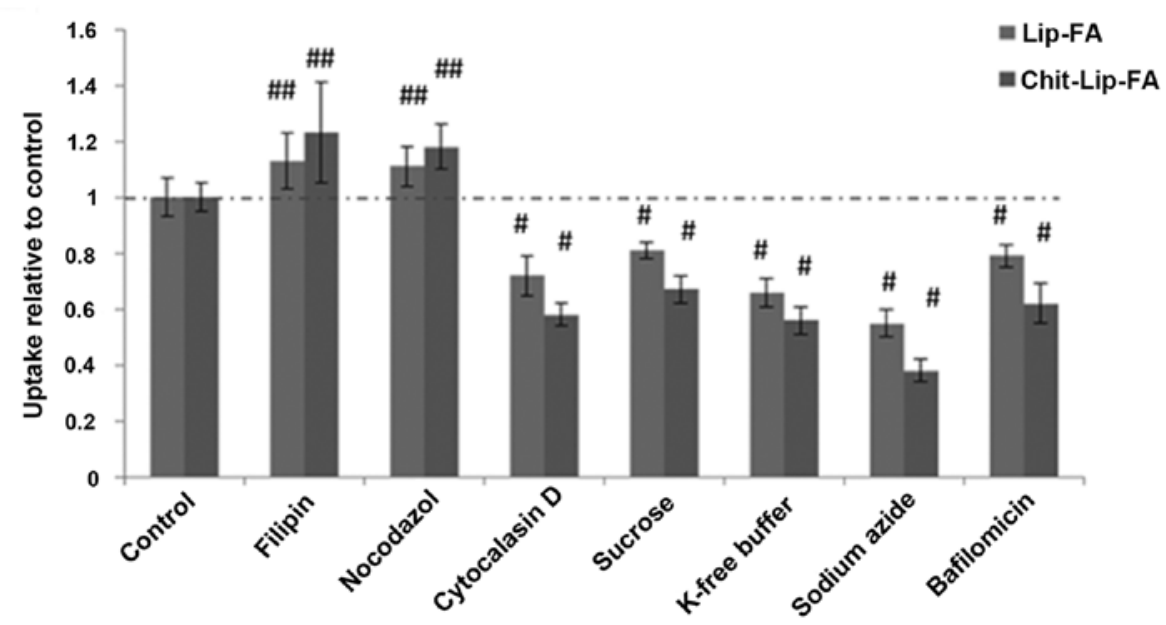

Figure 4. (A) Overall cellular uptake of uncoated (Lip-FA) and coated fluorescent liposomes (Chit-Lip-FA) at $1 \mathrm{mg} / \mathrm{ml}$ in HepG2 cells $\left(5 \times 10^{3}\right.$ cells/well) from 0.5 to $24 \mathrm{~h}$. ${ }^{*} \mathrm{P}<0.001,{ }^{* *} \mathrm{P}<0.05$. (B) Effects of different inhibitors on the internalization of uncoated and coated fluorescent liposomes $(1 \mathrm{mg} / \mathrm{ml})$ in HepG2 cells after $4 \mathrm{~h}$ of incubation. The data are normalized vs. their controls. ${ }^{~} \mathrm{P}<0.01$ (difference between control and treatment group); ${ }^{\# \#} \mathrm{P}<0.05$ (difference between control and treatment groups).

results are in agree with the internalization and cell viability experiments and support the hypothesis that chitosan-coated liposomes improved significantly the anti-inflammatory and anticancer functions of BA in liver cancer cells.

\section{Discussion}

Butyric acid (BA) is an important fatty acid with possible implications in cancer prevention and therapy, as previously shown (48). Despite its anti-inflammatory, immune-modulating, epigenetic and anticancer properties, its main crucial limits are based on the poor accumulation in target organs such as the liver where its metabolism could have a key function in the treatment of cancer conditions and altered lipidogenesis (49). This short-chain fatty acid (SCFA) is known to modulate the tissue microenvironment by inhibiting interleukin and cytokine secretion by fibroblasts and macrophages but also by cancer cells that can release growth factors that act in an autocrine or paracrine manner in order to stimulate their survival, metastasis and chemo-radioresistance. Interestingly, BA has shown anticancer properties against $\mathrm{HCC}$ cells principally based on its histone deacetylase (HDAC) inhibitory activity (50). Another study demonstrated the effects of BA on E-cadherin, vimentin, $\mathrm{N}$-cadherin markers and on TGF- $\beta 1$ in HCC cells (51).

In the present study, we produced and characterized biodegradable and biocompatible liposomes encapsulating BA, coated or uncoated with chitosan on their surface in order to increase both human cancer HepG2 cell uptake and BA internalization. Liposomes are among the most versatile and biodegradable nanocarriers used to increase the pharmacokinetic profile, stability and targeting of anticancer agents for both diagnosis and treatment (52). Chitosan is a positively charged polysaccharide at physiological $\mathrm{pH}$ with significant clinical applications as carriers of drugs after systemic or oral administration in mice and humans; in fact, chitosan was selected for its ability to resist degradation in 

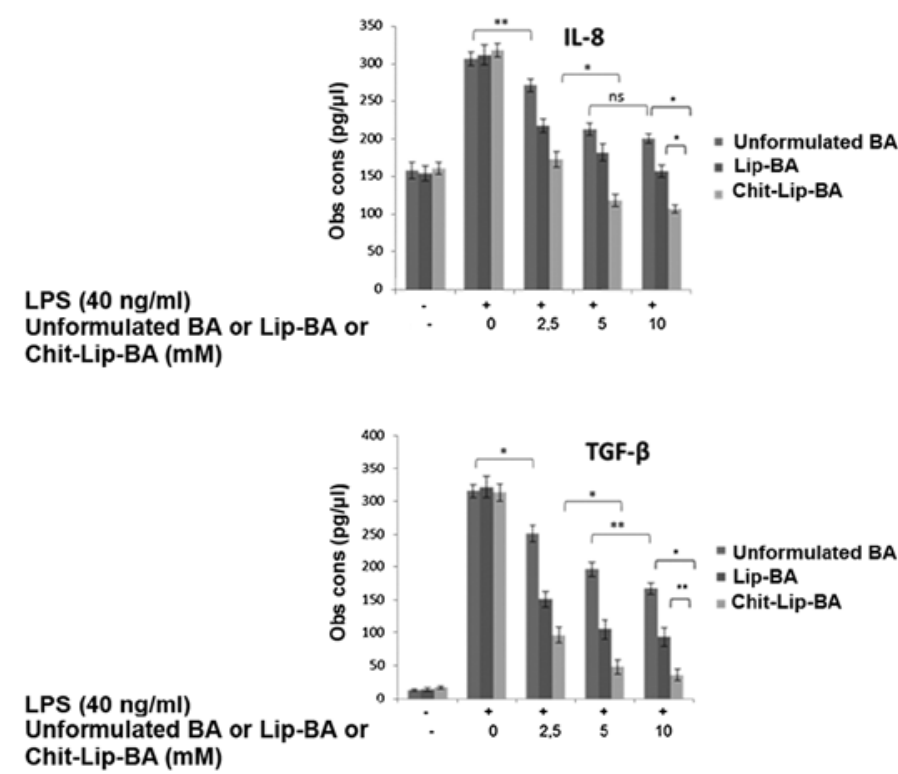

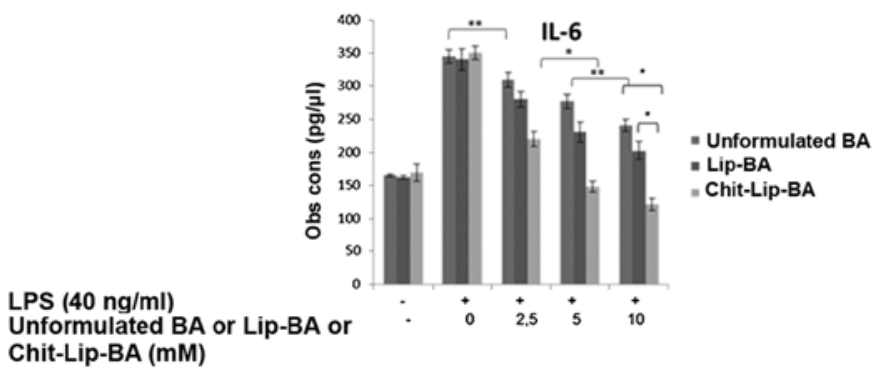

LPS $(40 \mathrm{ng} / \mathrm{ml})$ Unformulated BA or Lip-BA or

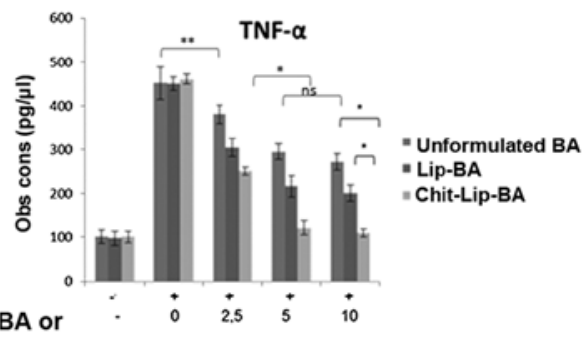

Figure 5. Anti-inflammatory properties of free BA (unformulated BA) or uncoated (Lip-BA) or coated liposomes loaded with BA (Chit-Lip-BA) on IL-8, IL-6, TGF- $\beta$ and TNF- $\alpha$ production in HepG2 cells $\left(1.2 \times 10^{5}\right.$ cells/well). Cells were treated with or without $0.1 \mathrm{ml}$ of $2.5,5.0$ or $10.0 \mathrm{mM}$ concentration of free BA or uncoated or coated liposomes loaded with BA for $5 \mathrm{~h}$ before exposure to lipopolysaccharides (LPS) (40 ng/ml) for $12 \mathrm{~h}$. "P<0.001; ${ }^{* *} \mathrm{P}<0.05$; ns, not significant.

the gastro-intestinal tract and for its muco-adhesive capacity in the intestinal lumen with interesting application for the oral delivery of drugs (53). Following the synthesis methods described above, the liposome distribution size was always in agreement with the presence or absence of surface coating with a mean value of approximately $100 \mathrm{~nm}$ that is well studied in the literature as an efficient nanocarrier model for delivery of anti-inflammatory and anticancer agents. Chitosan coating increased the overall liposome diameter of approximately 30-40 $\mathrm{nm}$ and changed their surface charge from negative to positive (Table I), an indirect demonstration of the efficient coating process. The presence of chitosan on the liposome surface always achieved the best biological effects in all the experimental conditions; in fact, their cell internalization efficiency was significantly greater than the uncoated liposomes at all incubation times in the HepG2 cells; internalization properties of this type of liposomes were supported by imaging with confocal microscopy. Moreover, on the basis of the results obtained with specific uptake inhibitors, we can hypothesize that both liposomes used the same internalization mechanism in the HepG2 cells characterized by an endocytic manner which use for their uptake the clathrin-coated pits and actin filaments. However, chitosan-coated nanocarriers appeared to be more dependent on these mechanisms when compared to the uncoated liposomes.

Comparing the cytotoxicity of free BA with both nanocarrier formulations, similar results were observed as suggested by greater anticancer effects induced by chitosan-coated liposomes with a reduction in the $\mathrm{IC}_{50}$ values at $72 \mathrm{~h}$ of more than $65 \%$ when compared to free BA. As evident by previously reported data, BA induces strong anti-inflammatory effects in the liver microenvironment and IL- 8 , IL-6, TNF- $\alpha$ and TGF- $\beta$, produced during inflammation, have a key function in liver cancer biology as in non-cancer diseases such as steatosis. The effects of BA on liver production of these interleukins have a translational value in oncology and hepatology. In fact, the use of nonsteroidal anti-inflammatory drugs decrease the incidence and/or recurrence of HCC (54). Inhibition of the inflammation status in the liver enhances various pharmacological therapies; for example, the combination therapy of zoledronic acid and sorafenib to treat advanced HCC is being evaluated in phase II studies (NCT01259193) (55). Numerous therapeutics have been designed to block cytokine receptors and downstream signaling pathways such as receptor kinases and STAT3 to inhibit inflammation-driven protumoral signals. IL-8 and IL-6 are both related to poor chemotherapeutics, specifically doxorubicin response and tumorigenicity in HCC (56). An interesting clinical trial on HCC cancer patients, demonstrated that serum IL-8 levels were a significant prognostic factor in terms of disease-free and overall survival. Moreover, patients with a serum IL-8 level of $>17.6 \mathrm{pg} / \mathrm{ml}$ had a poorer diseasefree survival than those with a level of $<17.6 \mathrm{pg} / \mathrm{ml}$ (median disease-free survival 4.7 vs. 19.2 months) (57). In addition, other small molecules such as TGF- $\beta$ and TNF- $\alpha$ play a crucial role in several liver disorders including cancer and steatosis (58) and are implicated in drug resistance processes, as example in sorafenib and doxorubicin treatments, as they upregulate the expression of multiple receptor tyrosine kinases (RTKs), including IGF1R, EGFR, PDGF $\beta R$, and FGFR1 in HCC cells (59).

Based on these considerations, many researchers have discussed the use of single inhibitors of IL- 8 , IL- 6 or TGF- $\beta$, also in association with anticancer drugs. But considering the multiple pathways involved in drug resistance processes as well as in cancer cell progression and survival, an integrated approach able to inhibit in a multiple manner more interleukins and growth factors in the liver, could be an innovative and useful integrative tool in HCC management. Here, we focused our attention on the role of BA as a modulator of the liver microenvironment exploiting its abilities in decreasing inflammation. 
On the basis of these aims, we investigated the abilities of two BA-loaded nanoformulations in hepatoblastoma (HB) cell uptake and cell viability status. The obtained results consistently showed that the chitosan-coated nanocarriers have the best internalization capabilities and biological activities compared to the uncoated one. These effects are in agreement with other previously publiched research of our group (by loading curcumin) (36). The anti-inflammatory activity obtained with the coated liposomes warrants the possible management of the liver cancer microenvironment through the use of these formulations. Overall, these results prompt us to perform additional experiments in animals to get definitive data concerning the anti-inflammatory properties of our formulations. In details, the expectation in the future is to take benefit of the pharmacological function of liposomes for the oral delivery of BA considering the ability of chitosan-coated nanocarriers, such as nanoemulsions, to accumulate in the iver after oral administration, as recently demonstrated (35). However, one limitation of our study is based on the absence of more biological studies such as gene expression and proteomic studies and our future investigations, planned by our research group, are based on the evaluation of different biological effects of BA in human cancer and non-cancer (such as fatty hepatocytes) liver cells considering the well known anti-steatotic effects of BA.

\section{Acknowledgements}

We thank the University Data Managers of the University Vanvitelli and University of Medicine of Salerno for assistance in the data analysis.

\section{Funding}

No funding was received.

\section{Availability of data and materials}

The datasets used during the present study are available from the corresponding author upon reasonable request.

\section{Authors' contributions}

VQ and MM coordinated and wrote the study. VQ and EA performed the experiments in cells and synthesis of liposomes. $\mathrm{MB}$ and $\mathrm{AG}$ coordinated the writing of the manuscript and the data analysis. MC, MP and AB coordinated scientifically the work and decided the choice of treatments performed. All authors read and approved the manuscript and agree to be accountable for all aspects of the research in ensuring that the accuracy or integrity of any part of the work are appropriately investigated and resolved.

\section{Ethics approval and consent to participate}

Not applicable.

\section{Patient consent for publication}

Not applicable.

\section{Competing interests}

No potential competing interests are disclosed.

\section{References}

1. Marra M, Sordelli IM, Lombardi A, Lamberti M, Tarantino L, Giudice A, Stiuso P, Abbruzzese A, Sperlongano R, Accardo M, et al: Molecular targets and oxidative stress biomarkers in hepatocellular carcinoma: An overview. J Transl Med 9: 171, 2011.

2. Jemal A, Bray F, Center MM, Ferlay J, Ward E and Forman D: Global cancer statistics. CA Cancer J Clin 61: 69-90, 2011.

3. Czaja AJ: Hepatic inflammation and progressive liver fibrosis in chronic liver disease. World J Gastroenterol 20: 2515-2532, 2014

4. Kershenobich Stalnikowitz D and Weissbrod AB: Liver fibrosis and inflammation. A review. Ann Hepatol 2: 159-163, 2003.

5. Li S, Tan H-Y, Wang N, Zhang ZJ, Lao L, Wong CW and Feng Y: The role of oxidative stress and antioxidants in liver diseases. Int J Mol Sci 16: 26087-26124, 2015.

6. Seki E and Schwabe RF: Hepatic inflammation and fibrosis: Functional links and key pathways. Hepatology 61: 1066-1079, 2015.

7. Zhang L, Song HY and Ji G: The joint pathway of metabolism and inflammation in nonalcoholic fatty liver disease. Zhonghua Gan Zang Bing Za Zhi 19: 395-397, 2011 (In Chinese).

8. Shivappa N, Hébert JR, Polesel J, Zucchetto A, Crispo A, Montella M, Franceschi S, Rossi M, La Vecchia C and Serraino D: Inflammatory potential of diet and risk for hepatocellular cancer in a case-control study from Italy. Br J Nutr 115: 324-331, 2016.

9. Alzahrani B, Isel TJ and Hebbard LW: Non-viral causes of liver cancer: Does obesity led inflammation play a role? Cancer Lett 345: 223-229, 2014.

10. Zhang LJ and Wang XZ: Interleukin-10 and chronic liver disease. World J Gastroenterol 12: 1681-1685, 2006.

11. Budhu A and Wang XW: The role of cytokines in hepatocellular carcinoma. J Leukoc Biol 80: 1197-1213, 2006.

12. Grivennikov SI, Greten FR and Karin M: Immunity, inflammation, and cancer. Cell 140: 883-899, 2010.

13. Wan S, Zhao E, Kryczek I, Vatan L, Sadovskaya A, Ludema G, Simeone DM, Zou W and Welling TH: Tumor-associated macrophages produce interleukin 6 and signal via STAT3 to promote expansion of human hepatocellular carcinoma stem cells. Gastroenterology 147: 1393-1404, 2014.

14. Hatting M, Spannbauer M, Peng J, Al Masaoudi M, Sellge G, Nevzorova YA, Gassler N, Liedtke C, Cubero FJ and Trautwein C: Lack of gp130 expression in hepatocytes attenuates tumor progression in the DEN model. Cell Death Dis 6: e1667, 2015.

15. Yamazaki K, Masugi Y and Sakamoto M: Molecular pathogenesis of hepatocellular carcinoma: Altering transforming growth factor- $\beta$ signaling in hepatocarcinogenesis. Dig Dis 29: 284-288, 2011.

16. Mamiya T, Yamazaki K, Masugi Y, Mori T, Effendi K, Du W, Hibi T, Tanabe M, Ueda M, Takayama T, et al: Reduced transforming growth factor-beta receptor II expression in hepatocellular carcinoma correlates with intrahepatic metastasis. Lab Invest 90: 1339-1345, 2010.

17. Korkaya H, Kim GI, Davis A, Malik F, Henry NL, Ithimakin S, Quraishi AA, Tawakkol N, D'Angelo R, Paulson AK, et al: Activation of an IL6 inflammatory loop mediates trastuzumab resistance in HER $2^{+}$breast cancer by expanding the cancer stem cell population. Mol Cell 47: 570-584, 2012.

18. Milagre CS, Gopinathan G, Everitt G, Thompson RG, Kulbe H, Zhong H, Hollingsworth RE, Grose R, Bowtell DD, Hochhauser D, et al: Adaptive upregulation of EGFR limits attenuation of tumor growth by neutralizing IL6 antibodies, with implications for combined therapy in ovarian cancer. Cancer Res 75: $1255-1264,2015$

19. Freudlsperger C, Bian Y, Contag Wise S, Burnett J, Coupar J, Yang $X$, Chen $Z$ and Van Waes C: TGF- $\beta$ and NF- $\kappa B$ signal pathway cross-talk is mediated through TAK1 and SMAD7 in a subset of head and neck cancers. Oncogene 32: 1549-1559, 2013.

20. Lin L, Amin R, Gallicano GI, Glasgow E, Jogunoori W, Jessup JM, Zasloff M, Marshall JL, Shetty K, Johnson L, et al: The STAT3 inhibitor NSC 74859 is effective in hepatocellular cancers with disrupted TGF-beta signaling. Oncogene 28: 961-972, 2009.

21. Bajaj JS, Hylemon PB and Younossi Z: The intestinal microbiota and liver disease. Am J Gastroenterol Suppl 1: 9-14, 2012. 
22. Juárez-Hernández E, Chávez-Tapia NC, Uribe M and BarberoBecerra VJ: Role of bioactive fatty acids in nonalcoholic fatty liver disease. Nutr J 15: 72, 2016.

23. Sharma V, Garg S and Aggarwal S: Probiotics and liver disease. Perm J 17: 62-67, 2013.

24. Endo H, Niioka M, Kobayashi N, Tanaka M and Watanabe T: Butyrate-producing probiotics reduce nonalcoholic fatty liver disease progression in rats: New insight into the probiotics for the gut-liver axis. PLoS One 8: e63388, 2013.

25. Mattace Raso G, Simeoli R, Russo R, Iacono A, Santoro A, Paciello O, Ferrante MC, Canani RB, Calignano A and Meli R: Effects of sodium butyrate and its synthetic amide derivative on liver inflammation and glucose tolerance in an animal model of steatosis induced by high fat diet. PLoS One 8: e68626, 2013.

26. Meijer K, de Vos P and Priebe MG: Butyrate and other shortchain fatty acids as modulators of immunity: What relevance for health? Curr Opin Clin Nutr Metab Care 13: 715-721, 2010.

27. Clemente JC, Ursell LK, Parfrey LW and Knight R: The impact of the gut microbiota on human health: An integrative view. Cell 148: $1258-1270,2012$

28. Saito H, Morizane T, Watanabe T, Kagawa T, Miyaguchi S, Kumagai $\mathrm{N}$ and Tsuchiya $\mathrm{M}$ : Differentiating effect of sodium butyrate on human hepatoma cell lines PLC/PRF/5, HCC-M and HCC-T. Int J Cancer 48: 291-296, 1991.

29. Banasiewicz T, Krokowicz Ł, Stojcev Z, Kaczmarek BF, Kaczmarek E, Maik J, Marciniak R, Krokowicz P, Walkowiak J and Drews M: Microencapsulated sodium butyrate reduces the frequency of abdominal pain in patients with irritable bowel syndrome. Colorectal Dis 15: 204-209, 2013.

30. Wu J and Zern MA: Modification of liposomes for liver targeting. J Hepatol 24: 757-763, 1996.

31. Rosso F, Quagliariello V, Tortora C, Di Lazzaro A, Barbarisi A and Iaffaioli RV: Cross-linked hyaluronic acid sub-micron particles: In vitro and in vivo biodistribution study in cancer xenograft model. J Mater Sci Mater Med 24: 1473-1481, 2013.

32. Vecchione R, Iaccarino G, Bianchini P, Marotta R, D'autilia F, Quagliariello V, Diaspro A and Netti PA: Ultrastable liquidliquid interface as viable route for controlled deposition of biodegradable polymer nanocapsules. Small 12: 3005-3013, 2016

33. Caraglia M, Marra M, Misso G, Lamberti M, Salzano G, De Rosa G and Abbruzzese A: Tumour-specific uptake of anticancer drugs: The future is here. Curr Drug Metab 13: 4-21, 2012

34. Camilleri JP, Williams AS, Amos N, Douglas-Jones AG, Love WG and Williams BD: The effect of free and liposomeencapsulated clodronate on the hepatic mononuclear phagocyte system in the rat. Clin Exp Immunol 99: 269-275, 1995.

35. Van Rooijen N and Sanders A: Kupffer cell depletion by liposome-delivered drugs: Comparative activity of intracellular clodronate, propamidine, and ethylenediaminetetraacetic acid. Hepatology 23: 1239-1243, 1996.

36. Vecchione R, Quagliariello V, Calabria D, Calcagno V, De Luca E, Iaffaioli RV and Netti PA: Curcumin bioavailability from oil in water nano-emulsions: In vitro and in vivo study on the dimensional, compositional and interactional dependence. J Control Release 233: 88-100, 2016.

37. Sasaki A, Murahashi N, Yamada H and Morikawa A: Syntheses of novel galactosyl ligands for liposomes and their accumulation in the rat liver. Biol Pharm Bull 17: 680-685, 1994.

38. Watanabe M, Pesando JM and Hakomori S: Effect of liposomes containing sodium butyrate conjugated with anti-CD19 monoclonal antibody on in vitro and in vivo growth of malignant lymphoma. Cancer Res 50: 3245-3248, 1990.

39. Altieri F, Di Stadio CS, Severino V, Sandomenico A, Minopoli G, Miselli G, Di Maro A, Ruvo M, Chambery A, Quagliariello V, et al: Anti-amyloidogenic property of human gastrokine 1. Biochimie 106: 91-100, 2014.

40. Di Stadio CS, Altieri F, Miselli G, Elce A, Severino V, Chambery A, Quagliariello V, Villano V, de Dominicis G, Rippa E, et al: AMP18 interacts with the anion exchanger SLC26A3 and enhances its expression in gastric cancer cells. Biochimie 121: 151-160, 2016.

41. Baravalle G, Schober D, Huber M, Bayer N, Murphy RF and Fuchs R: Transferrin recycling and dextran transport to lysosomes is differentially affected by bafilomycin, nocodazole, and low temperature. Cell Tissue Res 320: 99-113, 2005.
42. Barbarisi M, Iaffaioli RV, Armenia E, Schiavo L, De Sena G, Tafuto S, Barbarisi A and Quagliariello V: Novel nanohydrogel of hyaluronic acid loaded with quercetin alone and in combination with temozolomide as new therapeutic tool, CD44 targeted based, of glioblastoma multiforme. J Cell Physiol 233: 6550-6564, 2018

43. Qaddoumi MG, Gukasyan HJ, Davda J, Labhasetwar V, Kim KJ and Lee VH: Clathrin and caveolin-1 expression in primary pigmented rabbit conjunctival epithelial cells: Role in PLGA nanoparticle endocytosis. Mol Vis 9: 559-568, 2003.

44. Huang M, Ma Z, Khor E and Lim LY: Uptake of FITC-chitosan nanoparticles by A549 cells. Pharm Res 19: 1488-1494, 2002

45. Quagliariello V, Iaffaioli RV, Armenia E, Clemente O, Barbarisi M, Nasti G, Berretta M, Ottaiano A and Barbarisi A: Hyaluronic acid nanohydrogel loaded with quercetin alone or in combination to a macrolide derivative of rapamycin RAD001 (Everolimus) as a new treatment for hormone-responsive human breast cancer. J Cell Physiol 232: 2063-2074, 2017.

46. Nagasaki T, Hara M, Nakanishi H, Takahashi H, Sato M and Takeyama H: Interleukin- 6 released by colon cancer-associated fibroblasts is critical for tumour angiogenesis: anti-interleukin-6 receptor antibody suppressed angiogenesis and inhibited tumourstroma interaction. Br J Cancer 110: 469-478, 2014.

47. Meng J, Guo F, Xu H, Liang W, Wang C and Yang XD: Combination therapy using co-encapsulated resveratrol and paclitaxel in liposomes for drug resistance reversal in breast cancer cells in vivo. Sci Rep 6: 22390, 2016.

48. Gillet R, Jeannesson P, Sefraoui H, Arnould-Guérin ML, Kirkiacharian S, Jardillier JC and Pieri F: Piperazine derivatives of butyric acid as differentiating agents in human leukemic cells. Cancer Chemother Pharmacol 41: 252-255, 1998.

49. Siregar C, Wasito EB and Sudiana IK: Effect of butyric acid on p53 expression and apoptosis in colon epithelial cells in mice after treated with 9,10-dimethyl-1,2-benz(a)anthracene. Procedia Chem 18: 141-146, 2016

50. Coradini D and Speranza A: Histone deacetylase inhibitors for treatment of hepatocellular carcinoma. Acta Pharmacol Sin 26: 1025-1033, 2005

51. Wang HG, Huang XD, Shen P, Li LR, Xue HT and Ji GZ: Anticancer effects of sodium butyrate on hepatocellular carcinoma cells in vitro. Int J Mol Med 31: 967-974, 2013.

52. Caraglia M, De Rosa G, Salzano G, Santini D, Lamberti M, Sperlongano P, Lombardi A, Abbruzzese A and Addeo R: Nanotech revolution for the anti-cancer drug delivery through blood-brain barrier. Curr Cancer Drug Targets 12: 186-196, 2012.

53. Dash M, Chiellini F, Ottenbrite RM and Chiellini E: Chitosan - A versatile semi-synthetic polymer in biomedical applications. Prog Polym Sci 36: 981-1014, 2011.

54. Wu CY, Chen YJ, Ho HJ, Hsu YC, Kuo KN, Wu MS and Lin JT: Association between nucleoside analogues and risk of hepatitis $\mathrm{B}$ virus-related hepatocellular carcinoma recurrence following liver resection. JAMA 308: 1906-1914, 2012.

55. Cheng AL, Kang YK, Chen Z, Tsao CJ, Qin S, Kim JS, Luo R, Feng J, Ye S, Yang TS, et al: Efficacy and safety of sorafenib in patients in the Asia-Pacific region with advanced hepatocellular carcinoma: A phase III randomised, double-blind, placebocontrolled trial. Lancet Oncol 10: 25-34, 2009.

56. Park SY, Han J, Kim JB, Yang MG, Kim YJ, Lim HJ, An SY and Kim JH: Interleukin-8 is related to poor chemotherapeutic response and tumourigenicity in hepatocellular carcinoma. Eur J Cancer 50: 341-350, 2014

57. Ren Y, Poon RT, Tsui HT, Chen WH, Li Z, Lau C, Yu WC and Fan ST: Interleukin-8 serum levels in patients with hepatocellular carcinoma: Correlations with clinicopathological features and prognosis. Clin Cancer Res 9: 5996-6001, 2003.

58. Theron AJ Anderson R, Rossouw TM and Steel HC: The role of transforming growth factor beta-1 in the progression of HIV/ AIDS and development of non-AIDS-defining fibrotic disorders. Front Immunol 8: 1461, 2017.

59. Ungerleider $\mathrm{N}$, Han $\mathrm{C}$, Zhang J, Yao L and Wu T: TGF $\beta$ signaling confers sorafenib resistance via induction of multiple RTKs in hepatocellular carcinoma cells. Mol Carcinog 56: 1302-1311, 2017.

This work is licensed under a Creative Commons Attribution-NonCommercial-NoDerivatives 4.0 International (CC BY-NC-ND 4.0) License. 